\title{
The influence of the ratio of dimensions of rock samples on their tensile strength
}

\author{
Viktor Shalamanov ${ }^{1 *}$, Musa Shabdanov ${ }^{2}$ \\ ${ }^{1}$ T.F. Gorbachev Kuzbass State Technical University, 28 Vesennyaya, Kemerovo, the Russian \\ Federation \\ ${ }^{2}$ Oshskiy Technological University name of the acad. M.M. Adysheva, 723503, N. Isanov str., \\ 81,Kyrgyz Republic
}

\begin{abstract}
Annotation In the work, studies were carried out on the effect of the dimensions of rock samples and the shape of their end faces on the tensile strength limits. Sandstones, aleurolites and their interlayers were tested. The core diameter was $36-78 \mathrm{~mm}$, prevailing $50-70 \mathrm{~mm}$. Rocks are mainly medium- and fine-grained. The fracture of cores into pieces took place along thin layers of carbonaceous materials, aleurolites, cracks and cleavage, in places of accumulation and plaque of carbonaceous, carbonate and other weak substances in the form of continuous films, scattered spots and debris. All tests were carried out on the press in accordance with the recommendations of the current GOST, samples were divided by applying a load along the generatrix. It was found that the tensile strength of the test samples varied from 0.15 to $21 \mathrm{MPa}$. The results obtained proved conclusively that cores can be used to solve production and technical problems without preliminary treatment of their end surfaces at the ratio of heights to diameters from 0.31 to 1.6. This will allow to increase the volume of tests of samples taken in wells by $60 \%$, and obtain reliable information and thus more fully and reliably substantiate geomechanical conditions, Attachment and protection of mine workings and optimal angles of slopes of quarry sides and ledges at open method of coal mining. This issue has been little studied and requires further research in every geological-economic region of Kuzbass.
\end{abstract}

\section{Introduction}

For rational design of construction and reconstruction of the mining enterprises and maintaining the mining-construction works is required a solid data about strength properties the coalconttaining of rocks. We have recorded that as the depth of exploration wells increases, the yield of the core has increased significantly, from which it is not possible to produce rock samples. Cores are in many cases broken into separate parts on different weakening surfaces, and therefore it is not possible to produce images that meet the requirements of the current standards. This significantly complicated sampling of coalconttaining of rocks to determine the strength limits in accordance with the current GOSTs [1,2]. According to [1], the tensile strength shall be determined on cylindrical samples having a height $\mathrm{h}$ equal to diameter $\mathrm{d}$ (samples having a ratio $\mathrm{h} / \mathrm{d}=0.9-1.1$ can be used).

\footnotetext{
*Corresponding author: $\underline{\text { sva@kuzstu.ru }}$
} 
Analyzing the information accumulated in the laboratory for studying the strength properties of coalconttaining of rocks Kuzbass concluded that from drilling wells with a depth of more than $300 \mathrm{~m}$, the output of pieces of cores, height less than the diameter is $55 \%$ or more. In most cases, core pieces whose height-to-diameter ratio varied from 0.35 to 0.91 occupied more than $50 \%$ of their total volume. Especially painful output of pieces of cores (up to 65\%) is less than diameter of aleurolites and their interlayers, and from argyllites it is not possible to manufacture samples for testing at all, they in the core collector are already destroyed to pieces of not large size.

Another problem is that most of the macrodefective rocks are destroyed when they are formed into samples while working on a stone machine. Increasing the sampling of cores of the required size is not possible due to the low layer strength and variability of rock composition, especially those lying directly in the roof and soil of coal working beds. Due to the inability to produce the required number of cylindrical samples from the samples taken (not 10 from each rock variety) as required by the active GOST $[1,2]$, the laboratory usually carries out the most complete study of rocks for compression and significantly less for tension. Due to these reasons it is not possible to carry out tests of macrodefective rocks, that is, rocks on which the stability of workings and sides, ledges of quarries most depends. The lack of reliable data on the tensile strength of rocks makes it difficult to address the issues of geomechanical justification of protection and attachment of mining flows, prediction and calculation of the stability of the roof and the soil beam of workings, as here rocks perceive mainly tensile stresses.

\section{Results and discussion}

In order to solve the identified problems and increase the number of tests of weak and macrodefective rocks delivered to the laboratory, the effect of height and diameter reduction and the treatment state of core ends on tensile strength were studied.

Sandstones, aleurolites and their interlayers were tested, the diameter of cores was 35$80 \mathrm{~mm}$, the prevailing 50-70 $\mathrm{mm}$. Rocks are mainly medium- and small granular. Sandstones, aleurolites and their interlayers were tested, the diameter of cores was $35-80 \mathrm{~mm}$, the prevailing 50-70 mm. Rocks are mainly medium- and small granular. The breakdown of cores into pieces occurred mainly on thin layers of carbonaceous substances and aleurolites, cracks, cleavage, in places of accumulation and plaque of carbonaceous, carbonate and other weak substances in the form of continuous films and in places of prints of herbaceous vegetation.

Samples of which the ratio of height to diameter ranged from 0.3 to 1.5 without treating their ends and samples with treated ends were tested. Strength indices of samples with treated end surface made in accordance with the requirements of GOST [1] are taken as control ones and the results of all tests were evaluated according to them.

The $\mathrm{h} / \mathrm{d}$ values of the tested samples of each rock type are divided into 8 groups: 0.3 $0.5 ; 0.5-0.7 ; 0.7-0.9 ; 0.9-1.05 ; 1.05-1.2 ; 1.2-1.3 ; 1.3-1.4 ; 1.4-1.5$. Specific participation of samples of the same type in composition and structure in all groups of each breed variety was the sameTensile strength of the tested rocks varied from 0.1 to $20 \mathrm{MPa}$, but samples with a strength of less than $1 \mathrm{MPa}$ were encountered. In terms of tensile strength $\sigma_{p}$ studied rocks are divided into 8 groups: the first is not more than $1 \mathrm{MPa}$, the eighth is more than 15 $\mathrm{MPa}$ (Tables 1 and 2). The results were computer processed for each sample group in terms of $\mathrm{h} / \mathrm{d}$ and strength. The equations of linear, hyperbolic, logarithmic, exponential, and parabolic relationships have been determined to more fully assess the effect of the height and diameter ratio of the samples and the quality of treatment of their end surfaces on tensile strength. 
Tables 1 and 2 summarize the results of the tensile strength test of the samples in the $\mathrm{h} / \mathrm{d}$ range of 0.3 to 1.5 with both untreated end surfaces and samples manufactured according to the standard (benchmarks) of sandstones and aleurolites and their interlayers.

Table 1. Results of tests of rock samples with untreated ace surfaces.

\begin{tabular}{|c|c|c|c|c|c|c|c|c|c|}
\hline & & \multicolumn{8}{|c|}{ Height to diameter ratio $\mathbf{h} / \mathbf{d}$ for test samples } \\
\hline & : & $0.3-0.5$ & $0.5-0.7$ & $0.7-0.9$ & $0.9-1.05$ & 1.05-1.2 & $1.2-1.3$ & 1.3-1.4 & \begin{tabular}{|c|}
$\begin{array}{c}0.9-1.05 \\
\text { (standar } \\
\text { d } \\
\text { samples) }\end{array}$ \\
\end{tabular} \\
\hline $\begin{array}{l}\text { No- } \\
\text { more } 1\end{array}$ & $\begin{array}{l}n \\
\sigma_{p} \\
\mu \\
\eta\end{array}$ & $\begin{array}{c}17 \\
0.75 \\
28.8 \\
0.06-0.13 \\
\end{array}$ & \begin{tabular}{|c|}
21 \\
0.81 \\
26.4 \\
$0.25-0.11$ \\
\end{tabular} & $\begin{array}{c}25 \\
0.75 \\
24.1 \\
0.06-0.16 \\
\end{array}$ & \begin{tabular}{|c|}
26 \\
0.79 \\
25.2 \\
$0.04-0.19$ \\
\end{tabular} & $\begin{array}{c}19 \\
0.83 \\
27.4 \\
0.06-0.13 \\
\end{array}$ & $\begin{array}{c}19 \\
0.72 \\
27.9 \\
0.07-0.16 \\
\end{array}$ & \begin{tabular}{|c|}
21 \\
0.81 \\
27.6 \\
$0.05-0.17$ \\
\end{tabular} & $\begin{array}{c}22 \\
0.79 \\
23.8 \\
0.05-0.15\end{array}$ \\
\hline $1,1-2$ & $\begin{array}{l}n \\
\sigma_{p} \\
\mu \\
\eta \\
\end{array}$ & $\begin{array}{c}17 \\
1.48 \\
25.2 \\
0.04-0.17 \\
\end{array}$ & \begin{tabular}{|c|}
17 \\
1.51 \\
22.5 \\
$0.05-0.12$ \\
\end{tabular} & \begin{tabular}{|c|}
26 \\
1.46 \\
20.4 \\
$0.03-0.13$ \\
\end{tabular} & \begin{tabular}{|c|}
29 \\
1.53 \\
21.2 \\
$0.03-0.16$ \\
\end{tabular} & \begin{tabular}{|c|}
21 \\
1.65 \\
16.6 \\
$0.02-0.16$ \\
\end{tabular} & $\begin{array}{c}22 \\
1.57 \\
17 \\
0.04-0.17 \\
\end{array}$ & $\begin{array}{c}30 \\
1.62 \\
14.3 \\
0.04-0.1 \\
\end{array}$ & \begin{tabular}{|c|}
36 \\
1.54 \\
17.2 \\
$0.05-0.11$ \\
\end{tabular} \\
\hline $2,1-4$ & $\begin{array}{l}n \\
\sigma_{p} \\
\mu \\
\eta\end{array}$ & $\begin{array}{c}46 \\
3.24 \\
18.1 \\
0.05-0.19 \\
\end{array}$ & \begin{tabular}{|c|}
52 \\
3.05 \\
16.5 \\
$0.04-0.19$ \\
\end{tabular} & \begin{tabular}{|c|}
63 \\
3.15 \\
18.2 \\
$0.06-0.22$ \\
\end{tabular} & \begin{tabular}{|c|}
81 \\
3.15 \\
16.7 \\
$0.04-0.25$ \\
\end{tabular} & \begin{tabular}{|c|}
55 \\
3.21 \\
15.1 \\
$0.06-0.14$
\end{tabular} & $\begin{array}{c}32 \\
3.19 \\
19.2 \\
0.09-0.21 \\
\end{array}$ & \begin{tabular}{|c|}
21 \\
3.1 \\
17.1 \\
$0.05-0.18$ \\
\end{tabular} & \begin{tabular}{|c|}
115 \\
3.21 \\
16.2 \\
$0.05-0.17$
\end{tabular} \\
\hline $4,1-6$ & $\begin{array}{l}n \\
\sigma_{p} \\
\mu \\
\eta\end{array}$ & $\begin{array}{c}27 \\
4.99 \\
18.5 \\
0.05-0.09 \\
\end{array}$ & \begin{tabular}{|c|}
32 \\
4.91 \\
9.91 \\
$0.08-0.18$ \\
\end{tabular} & $\begin{array}{c}93 \\
5.06 \\
11 \\
0.08-0.13 \\
\end{array}$ & $\begin{array}{c}185 \\
5.05 \\
11.5 \\
0.06-0.11 \\
\end{array}$ & $\begin{array}{c}145 \\
5.05 \\
11.5 \\
0.03-0.15\end{array}$ & $\begin{array}{c}23 \\
4.81 \\
13.5 \\
0.11-0.17 \\
\end{array}$ & \begin{tabular}{|c|}
27 \\
4.95 \\
10.1 \\
$0.09-0.21$ \\
\end{tabular} & $\begin{array}{c}233 \\
5.03 \\
11.7 \\
0.06-0.02\end{array}$ \\
\hline $6,1-9$ & $\begin{array}{l}n \\
\sigma_{p} \\
\mu \\
\eta\end{array}$ & $\begin{array}{c}43 \\
7.75 \\
11.7 \\
0.09-0.15 \\
\end{array}$ & \begin{tabular}{|c|}
55 \\
7.59 \\
11.5 \\
$0.07-0.15$ \\
\end{tabular} & $\begin{array}{c}99 \\
7.33 \\
11.5 \\
0.04-0.1 \\
\end{array}$ & \begin{tabular}{|c|}
272 \\
7.3 \\
11.3 \\
$0.03-0.11$ \\
\end{tabular} & \begin{tabular}{|c|}
125 \\
7.3 \\
11.1 \\
$0.03-0.11$ \\
\end{tabular} & \begin{tabular}{|c|}
51 \\
7.22 \\
10.4 \\
$0.07-0.12$ \\
\end{tabular} & \begin{tabular}{|c|}
37 \\
7.55 \\
15.7 \\
$0.03-0.11$ \\
\end{tabular} & \begin{tabular}{|c|}
310 \\
7.35 \\
11.5 \\
$0.04-0.09$ \\
\end{tabular} \\
\hline $9,1-12$ & $\begin{array}{l}n \\
\sigma_{p} \\
\mu \\
\eta \\
\end{array}$ & $\begin{array}{c}25 \\
7.74 \\
11.4 \\
0.09-0.13 \\
\end{array}$ & \begin{tabular}{|c|}
29 \\
10.5 \\
8.3 \\
$0.04-0.15$ \\
\end{tabular} & \begin{tabular}{|c|}
48 \\
10.67 \\
8.2 \\
$0.04-0.12$ \\
\end{tabular} & \begin{tabular}{|c|}
43 \\
10.8 \\
7 \\
$0.05-0.15$ \\
\end{tabular} & \begin{tabular}{|c|}
30 \\
10.21 \\
9.1 \\
$0.05-0.16$ \\
\end{tabular} & $\begin{array}{c}36 \\
10.75 \\
9.07 \\
0.05-0.17 \\
\end{array}$ & \begin{tabular}{|c|}
29 \\
10.21 \\
10.5 \\
$0.07-0.19$ \\
\end{tabular} & \begin{tabular}{|c|}
49 \\
10.83 \\
7.3 \\
$0.05-0.17$ \\
\end{tabular} \\
\hline $12,1-15$ & $\begin{array}{l}n \\
\sigma_{p} \\
\mu \\
\eta\end{array}$ & $\begin{array}{c}21 \\
13.26 \\
12.7 \\
0.06-0.11 \\
\end{array}$ & \begin{tabular}{|c|}
22 \\
12.59 \\
13.1 \\
$0.03-0.13$ \\
\end{tabular} & \begin{tabular}{|c|}
26 \\
12.72 \\
14.5 \\
$0.05-0.17$ \\
\end{tabular} & \begin{tabular}{|c|}
29 \\
13.03 \\
13.4 \\
$0.05-0.12$ \\
\end{tabular} & $\begin{array}{c}27 \\
12.81 \\
14.9 \\
0.07-0.15\end{array}$ & $\begin{array}{c}21 \\
13.11 \\
12.7 \\
0.07-0.18 \\
\end{array}$ & \begin{tabular}{|c|}
23 \\
12.97 \\
14.7 \\
$0.06-0.21$ \\
\end{tabular} & $\begin{array}{c}31 \\
12.92 \\
11.99 \\
0.05-0.12 \\
\end{array}$ \\
\hline $\begin{array}{c}\text { More } \\
15\end{array}$ & $\begin{array}{l}n \\
\sigma_{p} \\
\mu \\
\eta\end{array}$ & - & - & - & $\begin{array}{c}21 \\
18.6 \\
16.3 \\
0.07-0.17\end{array}$ & $\begin{array}{c}19 \\
19.11 \\
17.2 \\
0.05-0.15\end{array}$ & $\begin{array}{c}23 \\
18.92 \\
18.1 \\
0.05-0.11\end{array}$ & $\begin{array}{c}21 \\
19.12 \\
19.3 \\
0.11-0.17\end{array}$ & $\begin{array}{c}27 \\
18.96 \\
14.5 \\
0.07-0.17\end{array}$ \\
\hline
\end{tabular}


Table 2. Test results reference exemples rocks.

\begin{tabular}{|c|c|c|c|c|c|c|c|c|c|}
\hline & & \multicolumn{8}{|c|}{ Height to diameter ratio $\mathrm{h} / \mathrm{d}$ for test samples } \\
\hline & 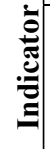 & $0.3-0.5$ & $0.5-0.7$ & $0.7-0.9$ & 0.9-1.05 & 1.05-1.2 & $1.2-1.3$ & 1.3-1.4 & $\begin{array}{c}\text { 0.9-1.05 } \\
\text { (standar } \\
\text { d } \\
\text { samples) }\end{array}$ \\
\hline $\begin{array}{l}\text { No- } \\
\text { more } 1\end{array}$ & $\begin{array}{l}n \\
\sigma_{p} \\
\mu \\
\eta\end{array}$ & $\begin{array}{c}45 \\
0.72 \\
28.3 \\
0.08-0.17 \\
\end{array}$ & \begin{tabular}{|c|}
21 \\
0.81 \\
26.4 \\
$0.25-0.11$ \\
\end{tabular} & \begin{tabular}{|c|}
25 \\
0.75 \\
24.1 \\
$0.06-0.16$ \\
\end{tabular} & $\begin{array}{c}26 \\
0.79 \\
25.2 \\
0.04-0.19 \\
\end{array}$ & $\begin{array}{c}19 \\
0.83 \\
27.4 \\
0.06-0.13 \\
\end{array}$ & $\begin{array}{c}19 \\
0.72 \\
27.9 \\
0.07-0.16 \\
\end{array}$ & $\begin{array}{c}21 \\
0.81 \\
27.6 \\
0.05-0.17\end{array}$ & $\begin{array}{c}22 \\
0.79 \\
23.8 \\
0.05-0.15 \\
\end{array}$ \\
\hline $1,1-2$ & $\begin{array}{l}n \\
\sigma_{p} \\
\mu \\
\eta\end{array}$ & $\begin{array}{c}196 \\
1.53 \\
19.6 \\
0.01-0.08\end{array}$ & $\begin{array}{c}191 \\
1.53 \\
19 \\
0.01-0.1\end{array}$ & $\begin{array}{c}265 \\
1.53 \\
17.9 \\
0.01-0.09\end{array}$ & $\begin{array}{c}215 \\
1.59 \\
22.5 \\
0.01-0.11\end{array}$ & $\begin{array}{c}216 \\
1.53 \\
18.4 \\
0.03-0.15\end{array}$ & $\begin{array}{c}227 \\
1.53 \\
20 \\
0.03-0.17\end{array}$ & $\begin{array}{c}187 \\
1.49 \\
18.3 \\
0.05-0.17\end{array}$ & $\begin{array}{c}233 \\
1.53 \\
18.3 \\
0.02-0.11\end{array}$ \\
\hline $2,1-4$ & $\begin{array}{l}n \\
\sigma_{p} \\
\mu \\
\eta\end{array}$ & $\begin{array}{c}263 \\
2.85 \\
19.2 \\
0.02-0.11\end{array}$ & \begin{tabular}{|c|}
286 \\
4.82 \\
10.3 \\
$0.01-0.08$
\end{tabular} & \begin{tabular}{|c|}
227 \\
4.8 \\
11.4 \\
$0.03-0.09$
\end{tabular} & $\begin{array}{c}258 \\
4.9 \\
11.4 \\
0.06-0.15\end{array}$ & $\begin{array}{c}219 \\
4.85 \\
11.2 \\
0.08-0.21\end{array}$ & $\begin{array}{c}149 \\
4.85 \\
11 \\
0.05-0.17\end{array}$ & $\begin{array}{c}141 \\
5.01 \\
10.1 \\
0.03-0.08\end{array}$ & $\begin{array}{c}263 \\
4.85 \\
11.3 \\
0.04-0.15\end{array}$ \\
\hline $4,1-6$ & $\begin{array}{l}n \\
\sigma_{p} \\
\mu \\
\eta\end{array}$ & $\begin{array}{c}142 \\
4.89 \\
12.5 \\
0.05-0.09\end{array}$ & $\begin{array}{c}165 \\
4.91 \\
9.91 \\
0.08-0.18\end{array}$ & $\begin{array}{c}225 \\
4.9 \\
11 \\
0.08-0.13\end{array}$ & $\begin{array}{c}255 \\
4.93 \\
11.5 \\
0.06-0.11\end{array}$ & $\begin{array}{c}216 \\
5.05 \\
11.5 \\
0.03-0.15\end{array}$ & $\begin{array}{c}146 \\
4.81 \\
11.9 \\
0.11-0.17\end{array}$ & $\begin{array}{c}137 \\
4.95 \\
10.1 \\
0.09-0.21\end{array}$ & $\begin{array}{c}233 \\
5.03 \\
11.7 \\
0.06-0.02\end{array}$ \\
\hline $6,1-9$ & $\begin{array}{l}n \\
\sigma_{p} \\
\mu \\
\eta\end{array}$ & $\begin{array}{c}83 \\
7.45 \\
11.7 \\
0.09-0.15\end{array}$ & \begin{tabular}{|c|}
95 \\
7.59 \\
11.5 \\
$0.07-0.15$
\end{tabular} & \begin{tabular}{|c|}
199 \\
7.33 \\
11.5 \\
$0.04-0.1$
\end{tabular} & $\begin{array}{c}118 \\
7.21 \\
11.6 \\
0.03-0.11\end{array}$ & $\begin{array}{c}89 \\
7.03 \\
10.1 \\
0.03-0.11\end{array}$ & \begin{tabular}{|c|}
80 \\
7.22 \\
10.4 \\
$0.07-0.12$
\end{tabular} & $\begin{array}{c}79 \\
7.51 \\
14.7 \\
0.03-0.18\end{array}$ & $\begin{array}{c}120 \\
7.15 \\
11.9 \\
0.04-0.09\end{array}$ \\
\hline $9,1-12$ & $\begin{array}{l}n \\
\sigma_{p} \\
\mu \\
\eta \\
\end{array}$ & $\begin{array}{c}49 \\
9.74 \\
8.48 \\
0.09-0.15 \\
\end{array}$ & \begin{tabular}{|c|}
51 \\
10.12 \\
7.3 \\
$0.04-0.15$ \\
\end{tabular} & \begin{tabular}{|c|}
48 \\
10.67 \\
8.2 \\
$0.04-0.12$ \\
\end{tabular} & $\begin{array}{c}65 \\
10.08 \\
9.4 \\
0.05-0.19 \\
\end{array}$ & $\begin{array}{c}55 \\
10.1 \\
12.1 \\
0.05-0.16 \\
\end{array}$ & \begin{tabular}{|c|}
46 \\
10.75 \\
9.07 \\
$0.05-0.17$ \\
\end{tabular} & $\begin{array}{c}49 \\
10.21 \\
16.5 \\
0.07-0.19 \\
\end{array}$ & $\begin{array}{c}55 \\
13.3 \\
8.3 \\
0.05-0.17 \\
\end{array}$ \\
\hline $12,1-15$ & $\begin{array}{l}n \\
\sigma_{p} \\
\mu \\
\eta\end{array}$ & - & \begin{tabular}{|c|}
26 \\
12.89 \\
12.1 \\
$0.03-0.13$
\end{tabular} & $\begin{array}{c}28 \\
12.92 \\
16.5 \\
0.05-0.17\end{array}$ & $\begin{array}{c}34 \\
13.19 \\
18.4 \\
0.05-0.12\end{array}$ & $\begin{array}{c}31 \\
12.81 \\
14.5 \\
0.07-0.19\end{array}$ & $\begin{array}{c}29 \\
13.41 \\
16.7 \\
0.07-0.25\end{array}$ & $\begin{array}{c}34 \\
12.97 \\
15.7 \\
0.06-0.27\end{array}$ & $\begin{array}{c}35 \\
12.99 \\
12.49 \\
0.05-0.21\end{array}$ \\
\hline
\end{tabular}

Note. The following designations are used in tables 1 and 2:

$\mathrm{n}$ - number of tests;

$\sigma_{p}$ - higher tensile strength, $\mathrm{MPa}$;

$\mu$ - coefficient of variation;

$\eta$ - correlation ratio.

Analysis of the results of the studies showed that for samples with untreated end surfaces the indicators do not differ practically from those obtained for standard samples produced in accordance with the requirements of GOST [1], the increase of the height of the sample up to $110 \mathrm{~mm}$ also did not affect the change of their tensile strength.

The information given in tabl. 1 and 2 clearly proves that there is no association between tensile strength and $\mathrm{h} / \mathrm{d}$ ratio, the value of the variation factors and the correlation ratio vary from 0 to 0.15 . There is no significant effect of the quality of treatment of the end surface of the samples on the average values of strength values of the same type in terms of composition and structure of rocks. The average strength values of samples with untreated and treated end faces are substantially equal. 


\section{Conclusions}

1.The studies clearly prove that in order to solve all production-technical problems, tensile strength in coal-bearing rocks can be obtained for samples of cylindrical shape, in which the ratio of height to diameter varies from 0.3 to 1.5 , including on samples without treated end surface.

2. This will allow to increase by $60 \%$ the number of laboratory studies and provide reliable information on tensile strength of weak mines with significant structural-textural weakening and, therefore, the most complete justification of geomechanical conditions for carrying out, fixing and mining of mining and coal mining by open method.

\section{References}

1. GOST 21153.3-85. Rocks. Methods for Determining Uniaxial Tensile Strength (1985)

2. GOST 21153.2-84. Rocks. Methods for determining the strength of uniaxial strength (1984)

3. S. Kostyuk, A. Gegreen, V. Meljnik, M. Lupeey, E3S Web Conf., 21, 01035 (2017)

4. S. Kostyuk, N. Bedarev, O. Lyubimov, A. Shaikhislamov, E3S Web Conf., 15, 01009 (2017)

5. S. Kostyuk, N. Bedarev, O. Lyubimov, A. Shaikhislamov, E3S Web Conf., 21, 01002 (2017) 